\title{
Application of Differential Evolution to Determine the HEPWM Angles of a Three Phase Voltage Source Inverter
}

\author{
N. Bahari ${ }^{1}$, Z. Salam ${ }^{2}$, Taufik ${ }^{3}$ \\ ${ }^{1}$ Power Electronics and Drives Group, Universiti Teknikal Malaysia Melaka, Malaysia Melaka \\ ${ }^{2}$ Power Electronics and Drives Group, Universiti Teknologi Malaysia, Johor Bahru, Malaysia Skudai \\ ${ }^{3}$ Department of Electrical Engineering, California Polytechnic State University, USA \\ E-mail: hazilina@utem.edu.my
}

\begin{abstract}
This paper presents an efficient Differential Evolution (DE) based solution for harmonic elimination pulse-width modulation (HEPWM). The aim is to solve for the set of transcendental equations that determine the switching angles of the HEPWM waveform. The objective function of the DE is designed to minimize (to near zero) the selected harmonics and at the same time allows for the fundamental component of the output voltage to be controlled independently. To verify the method, simulation is carried out using MATLAB simulink. The computed switching angles are applied to a three phase voltage source inverter. Typical results are shown and discussed.
\end{abstract}

\section{INTRODUCTION}

The elimination of specific harmonics from the given voltage and current waveform generated by a voltage-source inverter (VSI) has been dealt with in numerous researchers [1]-[15]. In literature, these methods are known as harmonic elimination pulse-width modulation (HEPWM). HEPWM methods remain of greatest interest for the control of highvoltage high power VSI, where the main concerns are the switching losses and power switch voltage stress. Applications of HEPWM include railway traction VSI, HVDC and large power motor drives. It provides an ideal solution, especially for VSI operated in the low switching frequency range [4]. The main challenge associated with HEPWM is to solve the nonlinear transcendental equations that yield multiple sets of solutions [1], [2].

In most cases, the HEPWM angles are calculated off-line, i.e. the angles are obtained using off-line computers and then stored in memory. They are called upon whenever the HEPWM waveform is to be constructed. This approach is also known as Programmed HEPWM [5], [6]. Various numerical techniques are possible; most common is the Newton-Raphson method. It produces accurate solutions and good convergence provided that the initial guesses for the angles is near the local minima [7]. However, if the initial value is not correctly chosen, it can result in large iteration cycles and at times, non-convergence. Other calculus-based approaches have been used. These include space vector modulation scheme [8], Walsh functions [9], homotopy-based computation [10] and resultant theory [11], [12], [13]. Certain improvements are reported using these methods, but the problem of determining the appropriate initial conditions remain unresolved.

Evolutionary algorithm is new class of non-calculus, search and optimization technique that has become very popular in many engineering applications. These methods search from a population of points instead of a single point as in conventional search and optimization processes. Furthermore they do not require a "suitable" initial value. The initial points can be randomly generated from the search space. Genetic algorithm (GA) is one example of evolutionary algorithm that has been used associated with HEPWM [14], [15].

Differential evolution (DE) algorithm is known to be a simple and fast evolutionary algorithm. It is similar to GA but with one main difference: DE adopts a mutation strategy that allows it to be self adaptive in the selection process [16]. Compared to GA, it consumes much shorter time to reach optimum point [17], [18]. Although recently introduced (in relation to other evolutionary algorithms), DE has been widely used in optimization problem. In this work, only DE is used to search for the HEPWM angles that will eliminate specified number of harmonics without comparing to latest advanced algorithms.

\section{APPLYING DifFERENTIAL EVOLUTION TO HEPWM}

\section{A. General}

DE utilized a greedy and less stochastic approach compared to other evolutionary algorithm [19]-[23]. It combines simple arithmetical operators with the classical operations of the recombination, mutation and selection to evolve from a randomly generated starting population to a final solution [24]. The basic idea behind DE is a scheme whereby it generates the trial vectors, $u_{i, G}$. In each step, the DE mutates vectors, $v_{i, G}$ by adding weighted, random vector differentials to them. If the fitness of the trial vector is better than the target, the target vector, $X_{i, G}$ is replaced by the trial vector in the next generation, $X_{i, G+1}$. Fig. 1 shows a simplified flow chart of DE operation.

The mutation variants in DE, which shows the difference between each individual in the population, plays significant role in the mutation operation. With the evolution of the population, the difference between each individual value will 
decrease, which will influence the convergence speed to reach optimum values.

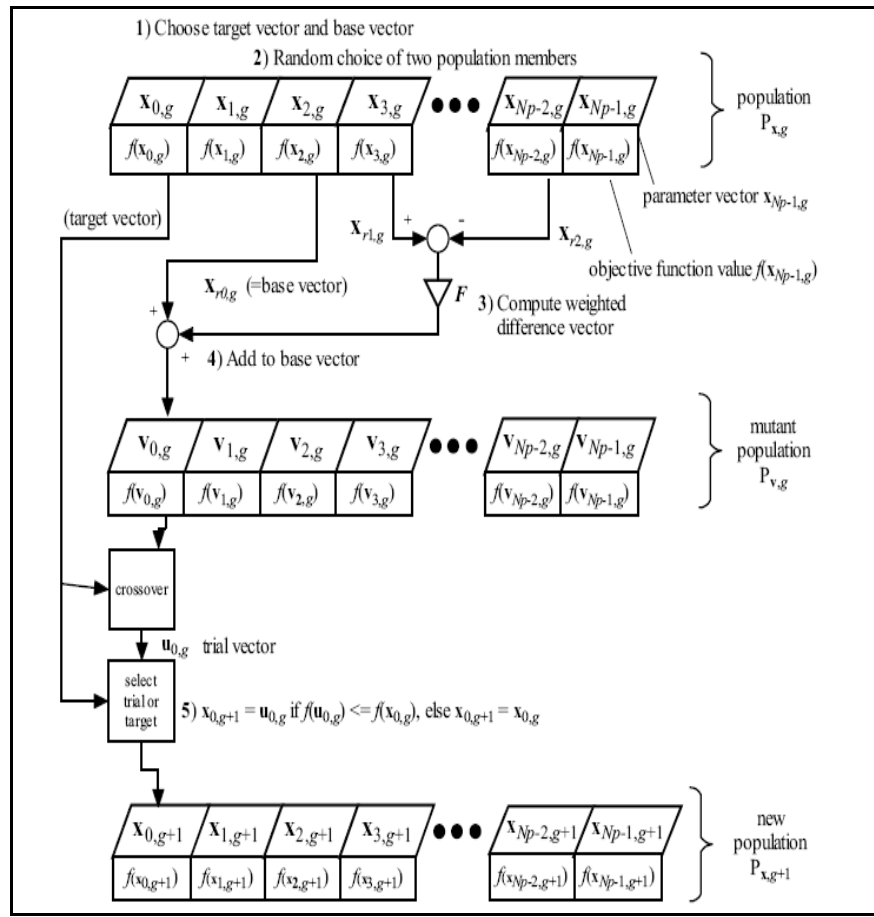

Fig.1 Flow of DE's generate-and-test loop [24]

\section{$B$ Application of DE to solve for HEPWM angles}

A generalized bipolar PWM waveform with $M$ number of chops per half-cycle is depicted in Fig. 2. It is assumed that this waveform is periodic and has half-wave symmetry with per unit amplitude. Such waveform represents the pole switching waveform of a three phase VSI, i.e. voltage from the one of the phases to the virtual ground. For the line to line voltage, the triplens (multiple of three) harmonics are cancelled. To obtain the amplitudes of all line to line harmonics (including fundamental), the pole switching waveform harmonics need to be multiplied by $\sqrt{3}$. If the three-phase VSI output has star network with neutral point $\mathrm{N}$, the harmonics of the phase voltage (with respect to $\mathrm{N}$ point) will have the same harmonics with the line to line but with amplitudes that of the pole switching waveform.

In Fig. 2, the basic square wave is chopped and a relationship between the number of chops and possible number of harmonics that can be eliminated is derived. The odd switching angles $\alpha_{1}, \alpha_{3}, \alpha_{5} \ldots$ etc. define the falling edge transitions and the even switching angles $\alpha_{2}, \alpha_{4}, \alpha_{6} \ldots$ etc. define the rising edge transitions. As the waveform is halfwave, only odd harmonics exist with a quarter-wave symmetric waveform, it results $B_{n}=0$ and are given by the following Fourier Series representation:

$$
A_{n}=\frac{4}{n \pi}\left[-1-2 \sum_{k=1}^{m}(-1)^{k} \cos \left(n \alpha_{k}\right)\right], n \text { is odd }
$$

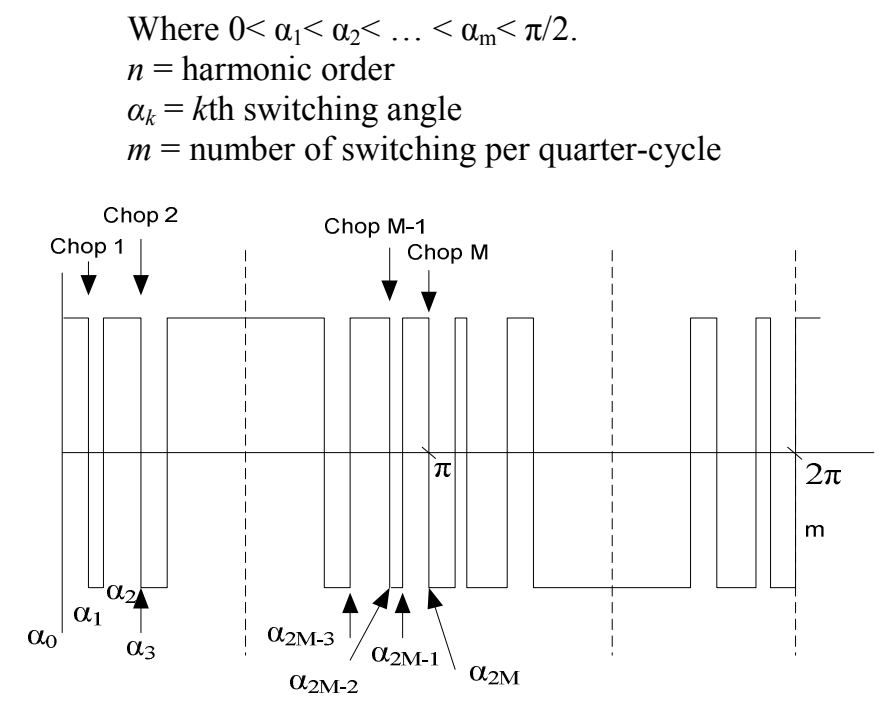

Fig. 2 Generalized quarter-wave symmetric HEPWM

Equation 1.1 has $m$ variables $\left(\alpha_{1}\right.$ to $\alpha_{m}$ ), where $m$ represented as number of switching per quarter-cycle and also it determine the number of harmonics eliminated, a set of solutions is obtainable by equating any $m-1$ harmonics to zero and assigning a value to the fundamental, NP1. These equations are nonlinear as well as transcendental in nature. The equations to eliminate $m-1$ lower order harmonic such as $3,5,7$ etc are in form of

$$
\begin{aligned}
& f_{1}(\alpha)= \frac{4}{\pi}\left[-1-2 \sum_{k=1}^{m}(-1)^{k} \cos \left(n \alpha_{k}\right)\right]-N P 1=\varepsilon_{1} \\
& f_{2}(\alpha)=\frac{4}{\pi}\left[-1-2 \sum_{k=1}^{m}(-1)^{k} \cos \left(n \alpha_{k}\right)\right]=\varepsilon_{2} \\
& \vdots \\
& f_{m}(\alpha)=\frac{4}{\pi}\left[-1-2 \sum_{k=1}^{m}(-1)^{k} \cos \left(n \alpha_{k}\right)\right]=\varepsilon_{m}
\end{aligned}
$$

where the variable $\varepsilon_{l}$ to $\varepsilon_{m}$ are normalized amplitudes of the harmonics to be eliminated and $N P 1$ is equivalent to the "modulation index" which is defined as

$N P 1=\frac{\left|V_{1}\right|}{V_{d c}}$

It should be noted that $0 \leq N P 1 \leq 1,\left|V_{l}\right|$ is the amplitude of the fundamental component and $V_{d c}$ is the DC input voltage source. The DE objective function to describe the harmonic elimination problem is defined as 
$f\left(\alpha_{1}, \alpha_{2}, \alpha_{3}, \ldots, \alpha_{m}\right)=\varepsilon_{1}^{2}+\varepsilon_{2}^{2}+\varepsilon_{3}^{2}+\ldots+\varepsilon_{m}^{2}$

The optimal switching angles are obtained by minimizing equation (4) when the subject to the following constraints:

$0<\alpha_{1}<\alpha_{2}<\alpha_{3}<\alpha_{4}<\alpha_{5} \ldots<\alpha_{m}<\frac{\pi}{2}$

The general structure of a DE program for HEPWM is shown in Fig. 3. The algorithm starts by initializing the target population of switching angles as an objective function. The DE parameters are set as follows: the population size, $P S=$ $10 * m$ (note: $m$ is number of harmonics to be eliminated), mutation factor (also known as the scale factor) $F=0.6$, crossover probability $C R=0.9$, harmonics tolerance $V T R=$ 0.0001 and the stopping criterion of the maximum number or generations $G_{\max }=300$. In the initialization operation, the target population (HEPWM angles) is randomly chosen within defined bounds, as indicated as $L_{a}$ and $H_{a}$ in Table 1 . It was found that the choice of the boundary has little effect on the performance of the algorithm, the wideness of the bounds required more iteration, however the projection remand the same, so long as the conditions in Eqn. (5) are satisfied.

For the next steps, the fitness value of each switching angles of the population is evaluated. If the fitness satisfies the predefined criteria, the final value is saved and the process is stopped. Otherwise, it will proceed to mutation operation. The mutation operation generates a mutant vector based on the initial target population. The derived mutant vector is considered as the secondary target population. Then the crossover operator is applied to the initial target and secondary target according to probabilistic scheme which is binomial and exponential crossover scheme to generate the trial vector within the crossover probability setting.

Finally, the trial vector of competes with its initial target population of switching angles for a position in the next generation. The aforementioned steps of the DE are repeated iteratively until the objective function of an individual vector is lower than predefined threshold or until a predefined total number of generations have been generated.

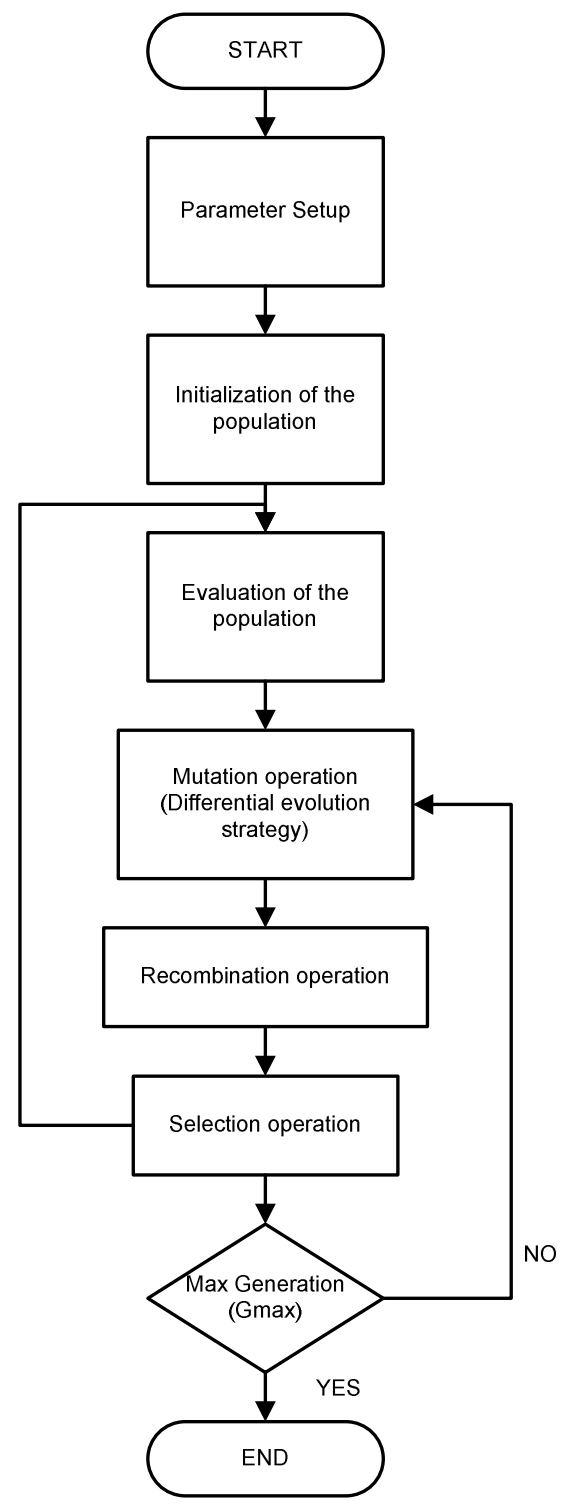

Fig. 3 Flow chart diagram of DE for HEPWM

TABLE 1: Upper and Lower bounds for HEPWM switching angles $\left(\alpha_{m}\right)$ for number of harmonics to be eliminated

\begin{tabular}{|c|c|c|c|c|c|c|c|c|c|c|c|c|c|c|}
\hline$m$ & Bound $/ \alpha$ & 1 & 2 & 3 & 4 & 5 & 6 & 7 & 8 & 9 & 10 & 11 & 12 & 13 \\
\hline \multirow{2}{*}{3} & $L_{a}$ & 0 & 20 & 40 & & & & & & & & & & \\
\hline & $H_{a}$ & 25 & 45 & 65 & & & & & & & & & & \\
\hline \multirow{2}{*}{5} & $L_{a}$ & 0 & 15 & 20 & 33 & 42 & & & & & & & & \\
\hline & $H_{a}$ & 25 & 30 & 40 & 50 & 70 & & & & & & & & \\
\hline \multirow{2}{*}{7} & $L_{a}$ & 0 & 5 & 15 & 25 & 35 & 45 & 52 & & & & & & \\
\hline & $H_{a}$ & 15 & 20 & 30 & 40 & 50 & 55 & 70 & & & & & & \\
\hline \multirow{2}{*}{9} & $L_{a}$ & 0 & 10 & 15 & 22 & 30 & 35 & 38 & 45 & 52 & & & & \\
\hline & $H_{a}$ & 15 & 25 & 30 & 35 & 40 & 45 & 50 & 60 & 70 & & & & \\
\hline \multirow{2}{*}{11} & $L_{a}$ & 0 & 5 & 12 & 18 & 20 & 27 & 32 & 38 & 42 & 45 & 52 & & \\
\hline & $H_{a}$ & 12 & 15 & 25 & 27 & 35 & 38 & 45 & 50 & 55 & 58 & 70 & & \\
\hline \multirow{2}{*}{13} & $L_{a}$ & 0 & 5 & 9 & 15 & 19 & 25 & 27 & 32 & 36 & 40 & 45 & 50 & 54 \\
\hline & $H_{a}$ & 7 & 11 & 16 & 21 & 26 & 30 & 34 & 39 & 42 & 48 & 53 & 59 & 70 \\
\hline
\end{tabular}


After obtaining the switching angles, they are stored in memory and called upon whenever the HEPWM is to be applied to an inverter. The circuit of a three-phase voltage source inverter is shown in Fig. 4. The harmonics of interests are the pole switching waveform $\mathrm{V}_{\mathrm{RG}}$ output voltage, line to neutral output voltage $\mathrm{V}_{\mathrm{RN}}$ and line to line output voltage $\mathrm{V}_{\mathrm{RY}}$. The specifications of the VSI are as follows: $\mathrm{V}_{\mathrm{DC}}=200 \mathrm{~V}_{\mathrm{dc}}$, fundamental frequency $=50 \mathrm{~Hz}, \mathrm{Z}_{1}=\mathrm{Z}_{2}=\mathrm{Z}_{3}=$ $4.5 \mathrm{mH} / 0.12 \Omega$ in series.

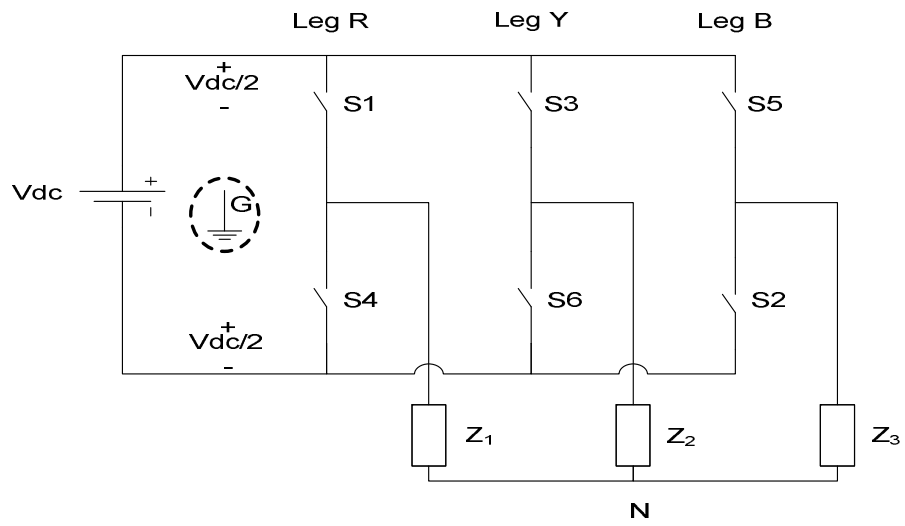

Fig. 4 Three-phase voltage source inverter

\section{RESULTS AND DisCUSSIONS}

The DE algorithm to solve for HEPWM angles is programmed in MATLAB. The trajectories for the switching angles $\left(\alpha_{1}\right.$ to $\left.\alpha_{\mathrm{m}}\right)$ versus the per unit amplitude of the fundamental component of the pole switching waveform (NP1) for $m=3,7,11$ and 13 are shown in Fig. 5(a)-(d), respectively. The results obtained are very similar to the Newton Raphson approach published in Reference [3],[4].

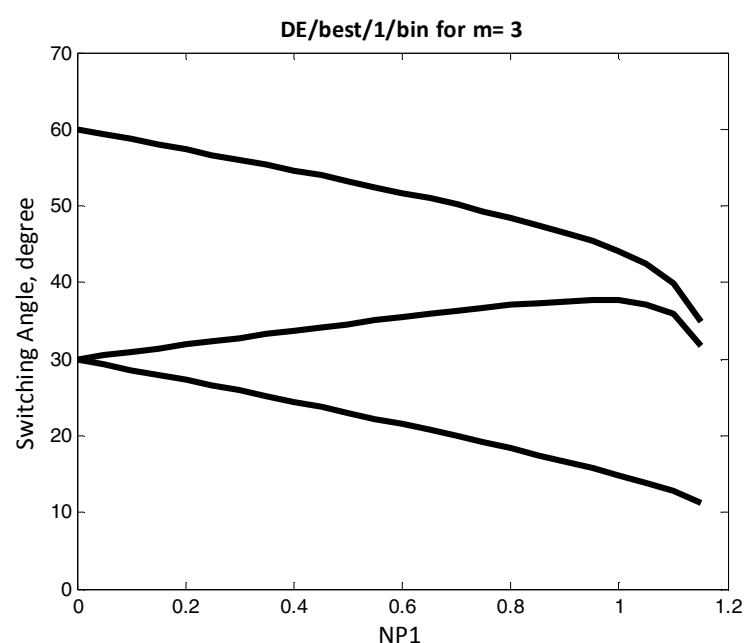

(a)

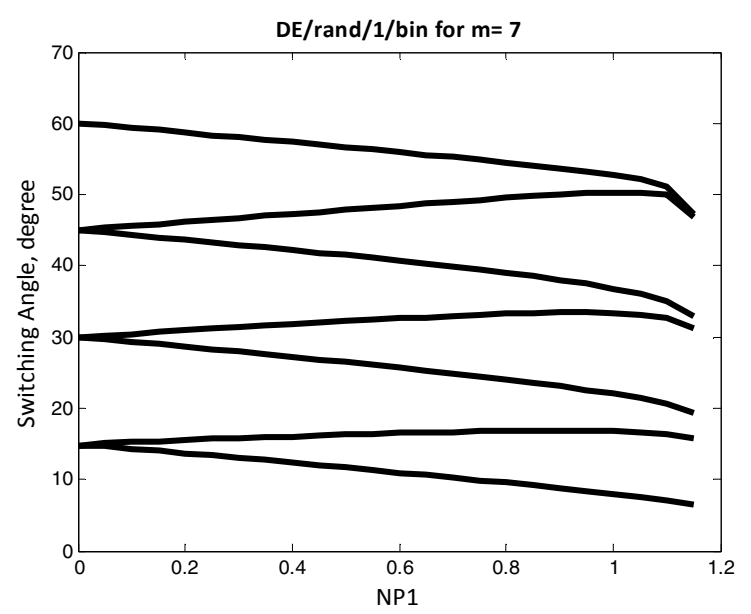

(b)

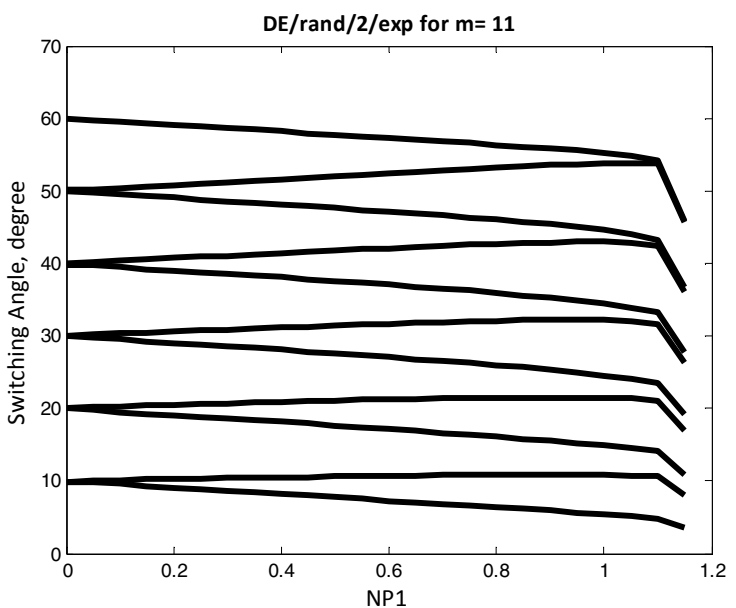

(c)

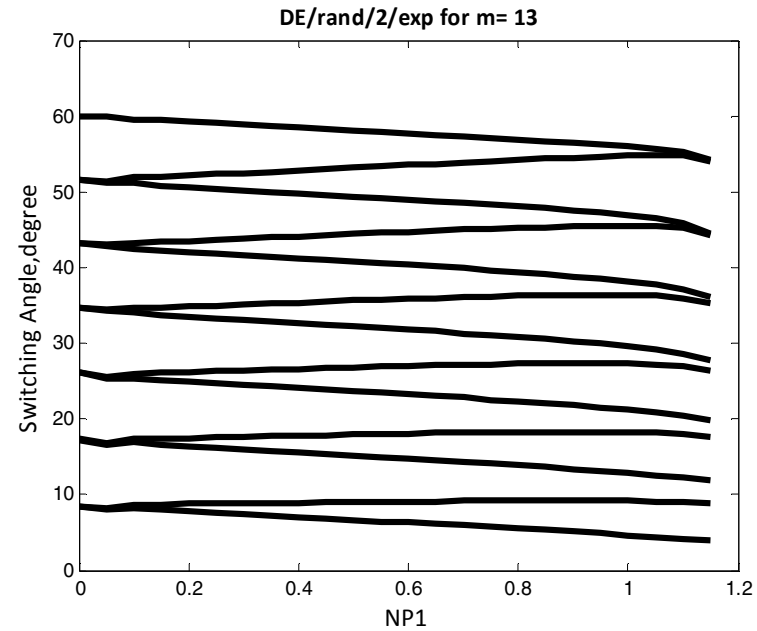

(d)

Fig. 5 Trajectories of switching angles for an odd number of switching per quarter cycle. (a) $m=3$, (b) $m=7$, (c) $m=11$, (d) $m=13$ 
Fig. 6(a) shows the pole switching waveform of a threephase inverter (i.e. voltage from phase $R$ to the virtual ground) for $m=9$ and $N P 1=0.45$. Fig. 6(b) shows its spectra. As expected, the selected harmonics are correctly eliminated but the triplens still remain in the pole switching waveform. The amplitude is correctly calculated to correspond for $N P 1=$ 0.45 , i.e. $45 \mathrm{~V}$ for $\mathrm{V}_{\mathrm{DC}}=200 \mathrm{~V}$ (note that $\mathrm{V}_{\mathrm{RG}}=1 / 2 \mathrm{~V}_{\mathrm{DC}}$ ). Fig 7 (a) shows the voltage of phase $R$ with respect to the neutral point of the three phase output, $V_{R N}$. The corresponding spectra are shown in Fig 7(b). The triplens are now cancelled and the first un-eliminated harmonics appears at the $29^{\text {th }}$. In general the first un-eliminated harmonic is given as $(3 m+2)$. The amplitude still remains at $45 \mathrm{~V}$. In Fig. 8(a), the line to line output voltage $\left(V_{R Y}\right)$ is shown, with its corresponding spectra in Fig. 8(b). The spectra are similar to $V_{R N}$, but all the harmonics (and fundamental) components are multiplied by square root three.

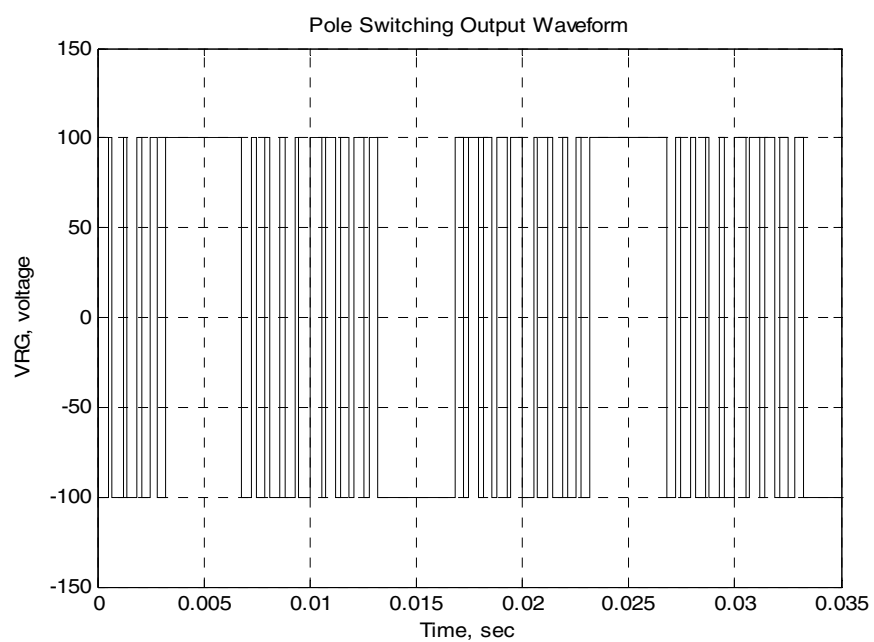

(a)

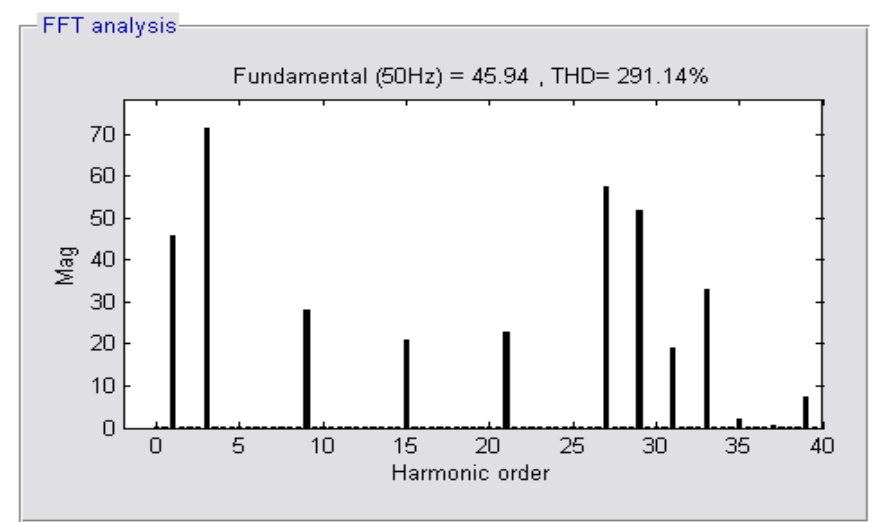

(b)

Fig. 6 Pole Switching Waveform of Three-Phase HEPWM Inverter for $m=9$. (b) Spectra of the output voltage waveform.

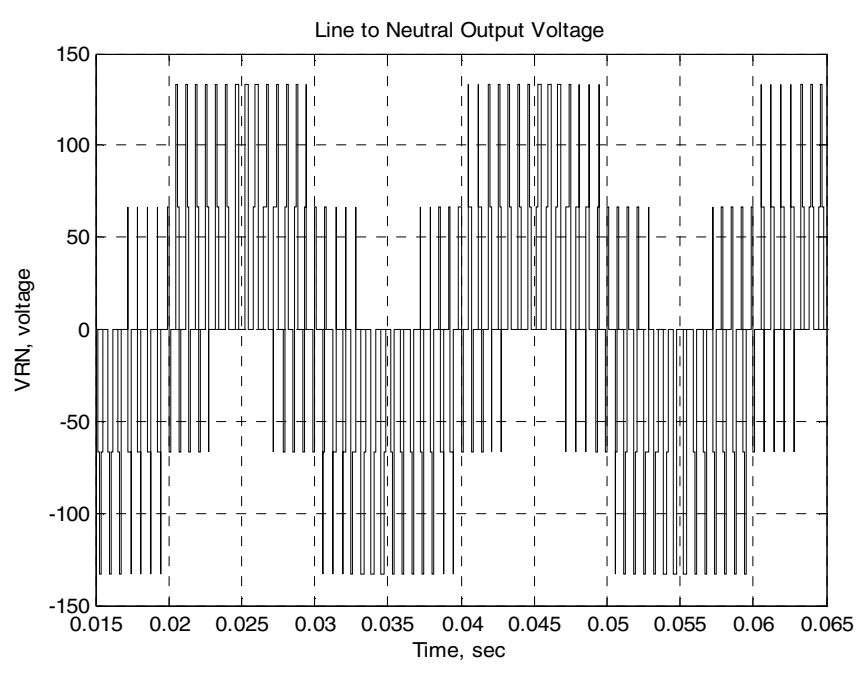

(a)

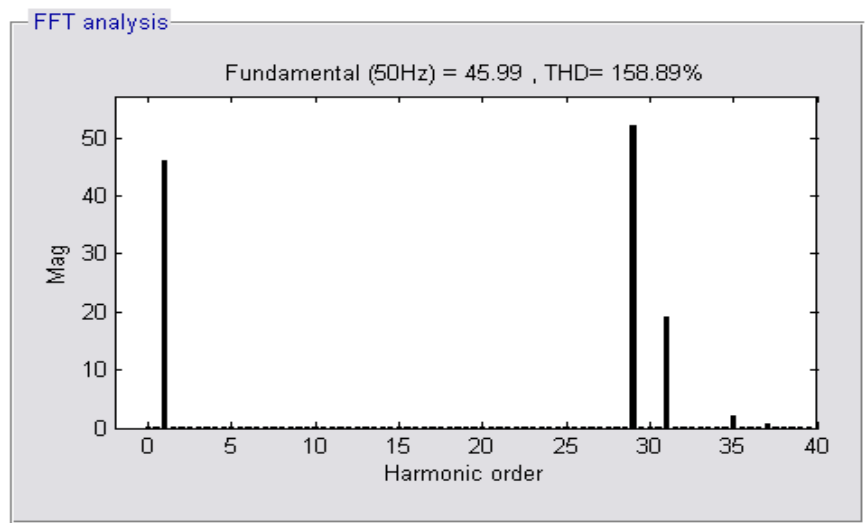

(b)

Fig. 7 Waveform of voltage of phase $\mathrm{R}$ with respect to the neutral point of the three phase output, $N$ for $m=9$. (b) Spectra of the output voltage waveform

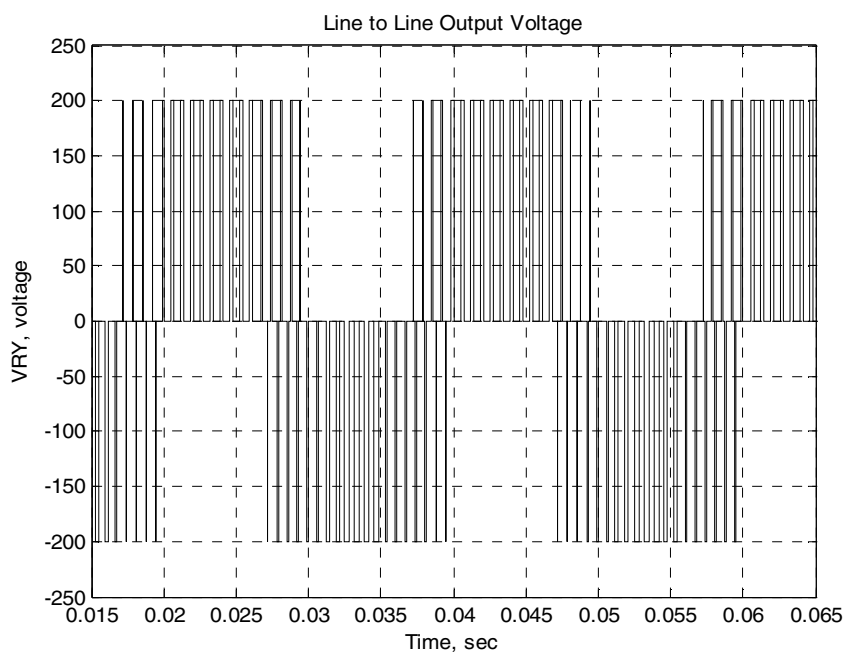

(a) 


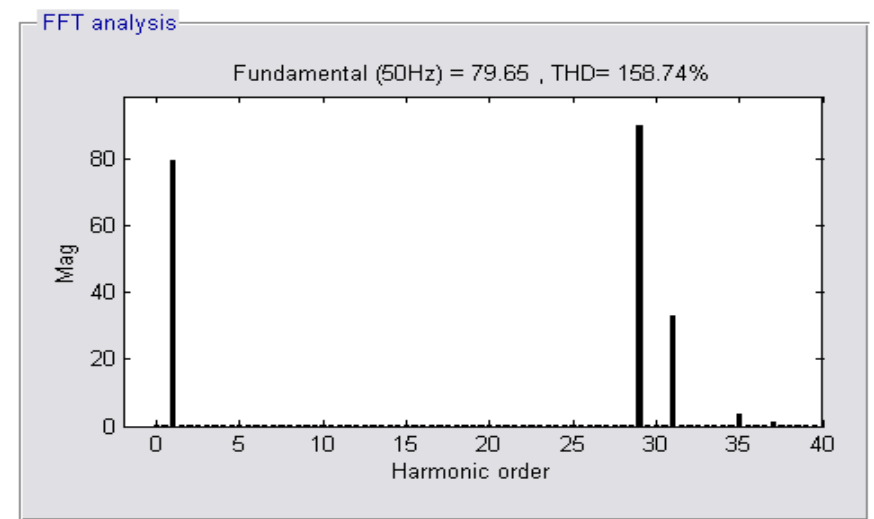

(b)

Fig. 8 Waveform of line to line voltage $\left(V_{R Y}\right)$ of the three phase output for $m=9$. (b) Spectra of the output voltage waveform

\section{CONCLUSION}

This paper has outlined the approach to use Differential Evolution search method to determine the switching angles of HEPWM. It has been shown that the method can accurately compute the HEPWM switching angles without having to make "correct" guesses on the initial values of the switching angles. Simulations are carried out to verify the algorithm when applied to a three phase inverter. The results are found to be in close agreement with the common knowledge of HEPWM and three phase inverter.

\section{REFERENCES}

[1] H.S. Patel and R.G. Hoft, "Generalized techniques of harmonic elimination and voltage control in thyristor inverters: Part I - harmonic elimination," IEEE Trans. Ind. Applicat., 1973, vol. IA-9, no.3, pp. 310-317.

[2] H.S. Patel and R.G. Hoft, "Generalized techniques of harmonic elimination and voltage control in thyristor inverters: Part II- voltage control technique," IEEE Trans. Ind. Applicat., 1974, vol. IA-10, no.5, pp. 666-673.

[3] J.A. Taufiq, B. Mellitt, and C.J. Goodman, "Novel algorithm for generating near optimal PWM waveforms for AC traction drives," IEEE Proceedings, 1986, vol. 133, Pt. B, no. 2, pp. 85-93.

[4] Z. Salam, "An on-line harmonic elimination pulse width modulation scheme for voltage source inverter," J. on Power Electronics, 2010, vol. 10, no. 1, pp 1-8.

[5] P. Enjeti, P.D. Ziogas and J.F. Lindsay, "Programmed PWM techniques to eliminate harmonics: A critical evaluation," IEEE Trans. Ind. Applicat., 1990, vol. 26, no.2, pp. 302-316.

[6] S.R. Bowes and D. Holliday, "Optimal regular-sampled PWM inverter control techniques," IEEE Trans. on Ind Electronics, 2007, vol. 54, no. 3, pp.1547-1559.

[7] P. Enjeti, and J.F. Lindsay, "Solving nonlinear equations of harmonic elimination PWM in power control," Electronics Letters, 1987, vol. 23 , no. 12 , pp. 656-657.

[8] S.R. Bowes and S. Grewal, "Novel space-vector-based harmonic elimination inverter control," IEEE Trans. on Ind. Applicat., 2000, vol. 36 , no. 2, pp. 549-557.

[9] T.J. Liang, , R.M. O'Connell and R.G. Hoft, "Inverter harmonic reduction using Walsh function harmonic elimination method," IEEE Trans. on Power Electronics, 1997, vol. 12, no. 6, pp.971 - 982.

[10] T. Kato, "Sequential homotopy-based computation of multiple solutions for selected harmonic elimination in PWM inverters," IEEE Trans. Circuits and Systems I: Fundamental Theory and Applications, 1999, vol. 46, no. 5, pp.586-593.
[11] J.N. Chiasson, L.M. Tolbert, K.J. McKenzie and Du Zhong, "Elimination of harmonics in a multilevel converter using the theory of symmetric polynomials and resultants," IEEE Trans. on Control Systems Technology, 2004, vol.13, no. 2. pp. 216-223.

[12] D. Zhong, L.M. Tolbert and J.N. Chiasson, "Active harmonic elimination for multilevel converters," IEEE Trans. on Power Electronics, 2006, vol. 21, no. 2, pp.459- 469.

[13] L.M. Tolbert, J.N. Chiasson, D. Zhong and K.J. McKenzie, "Elimination of harmonics in a multilevel converter with nonequal DC sources," IEEE Trans. on Industry Applicat., 2005, vol. 41, no. 1, pp. 75-82.

[14] M.S.A. Dahidah and V.G. Agelidis, "Selective harmonic elimination PWM control for cascaded multilevel voltage source converters: A generalized formula," IEEE Trans. on Power Electronics, 2008, vol. 23 , no. 4 , pp. $1620-1630$.

[15] B. Ozpineci, L.M. Tolbert and J.N. Chiasson, "Harmonic optimization of multilevel converters using genetic algorithms," IEEE Power Electronics Letters, 2005, vol. 3, no. 3, pp. 92-95.

[16] R. Storn, "System design by constraint adaptation and differential evolution," IEEE Trans. on Evolutionary Computation, 1999, vol. 2, pp. 82-102.

[17] R. Storn and K. Price, "Differential evolution: A simple and efficient heuristic strategy for global optimization over continuous space," $J$. of Global Optimization, 1997, vol. 11, Dordrecht, pp. 341-359.

[18] D. Karaboğa and S.Ŏ kdem, "A simple and global optimization algorithm for engineering problems: Differential evolution algorithm," Turk J. Elec. Engin, 2004, vol. 12, no. 1, pp 53-60.

[19] Z. Daniela, "A comparative analysis of crossover variants in differential evolution," Proceeding of International Multiconference on Computer Science and Information Techology, 2007, pp. 171-181.

[20] S. Bidyadhar, J. Debashiha, and M. G. Madan, "Memetic differential evolution trained neural networks for nonlinear system identification," IEEE Conf. Ind. Inform. Syst, 2008, pp.1-6.

[21] A. Youyun, and C. Hongqin, "Experimental study on differential evolution strategies," WRI Global Congress on Intelligent Systems, 2009, vol. 2, pp.19-24.

[22] Changshou Deng, et al, "New differential evolution algorithm with a second enhanced mutation operator," Intern.Workshop on Intelligence Syst. Appl., 2004, pp. 1-4. .

[23] E. M. Montes, J. V. Reyes and A. C. C. Carlos, "A comparative study of differential evolution variants for global optimization," Proceedings on Genetic and Evolutionary Computation, 2006, pp.485-492.

[24] K. Price, R. Storn and J. Lampinen, "Differential evolution: A practice approach to global optimization," Springer, 2005, New York. 